\title{
Research on the Efficiency of China's Logistics Industry in the Context of High-Quality Economic Development: Based on DEA-Malmquist Index Model
}

\author{
YU Yong \\ School of Business Administration \\ Hunan University of Technology and Business \\ Changsha, Hunan 410000 \\ China
}

\begin{abstract}
In order to investigate the development efficiency of China's logistics industry under the background of high-quality economy, the article constructs an evaluation index system based on the development of the logistics industry in 31 provinces of China from 2010 to 2019, and adopts the DEA-Malmquist index model to conduct static and dynamic analysis of the development efficiency of China's logistics industry. The study found that the regional development imbalance of China's logistics industry is more prominent. Finally, the article puts forward policy recommendations for the high-quality development of China's logistics industry in terms of the five development concepts and improving total factor productivity.
\end{abstract}

Keywords: logistics industry, logistics efficiency, DEA model, Malmquist index

Fund projects : Hunan Provincial Social Science Foundation Project : Base Issue "Research on Innovation and Development of Modern Supply Chain in Hunan in the Context of High Quality Economy” (19JD17 )

\section{Introduction}

At present, China's economy is "shifting from the stage of high-speed growth to the stage of high-quality development", and is in a critical period of transforming its development mode, optimizing its economic structure and transforming its growth momentum. There is an urgent need to build a modern economic system. High-quality development will be the latest direction of China's economic development. As the basic, pilot, global industry of national economic development, the logistics industry is the artery of economic development and plays an important strategic role in the process of national economic development. The Chinese government has introduced a number of policies to promote the high-quality development of logistics industry. Meanwhile, driven by the new technological revolution, China's logistics industry has been developing rapidly in recent years, expanding in scale, new technologies have been widely applied and promoted. The high-quality development of logistics has been an important part of the high-quality development of the economy.

The article aims to study the efficiency relationship between input and output of China's logistics industry, analyze the development efficiency, development level and problems of the logistics industry in 31 provinces and four regions in the context of high-quality economic development, and put forward relevant policy recommendations in order to achieve the unification of the high-quality development of the logistics industry and the national economy.

\section{Literature Review}

Research results on the development efficiency of the logistics industry are more abundant. Experts and scholars have studied the development efficiency of the logistics industry from both micro-level and macro-level perspectives.

Micro-level logistics efficiency focuses on aspects such as the performance of logistics companies, as XIAO Qian-wen (2017) analyzed the business efficiency of reverse logistics enterprises ${ }^{[1]}$; HAN Dong-ya (2019) chose 80 listed logistics companies as a sample to empirically analyze the efficiency of China's logistics industry and investigate the technical efficiency and influencing factors of China's logistics industry ${ }^{[2]}$.

Macro-level studies focus on the logistics efficiency of a region. For instance, WANG Bo (2019) conducted a comprehensive evaluation and analysis of logistics efficiency in the regions along the Belt and Road in China ${ }^{[3]}$; YU Jiali (2018) and Cao Bingru (2020) analyzed the spatial and temporal evolution of logistics industry efficiency and its influencing factors in the Yangtze River Economic Zone ${ }^{[4][5]}$; Mei Guoping (2019) based on the three-stage The DEA model was used to measure the efficiency of the logistics industry in East China ${ }^{[6]}$. 
In addition, relevant experts and scholars further carried out relevant in-depth research specifically on the logistics efficiency of a province and city in China.

In summary, the DEA model is a relatively common research method in logistics efficiency research. In terms of the scope of research, most scholars choose to study the logistics efficiency of a region or a specific province, but relatively little research on the comparative analysis of logistics efficiency nationwide in the context of high-quality economy. Based on this, I choose to use the DEA-Malmquist index model to conduct a static and dynamic comparative analysis of the logistics efficiency of 31 provinces in China.

\section{Selection of the Evaluation Indicator System}

The division of China's four regions in this study refers to Marketization Index of China's Provinces: Neri Report 2018.Based on the full reference of existing research, and through the form of expert consultation, the logistics evaluation index system was constructed from the two dimensions of input and output. Details are shown in Table 1.

Table 1 Logistics Industry Efficiency Assessment Index System

\begin{tabular}{|l|l|l|}
\hline \multirow{4}{*}{ Inputs } & First Class Indicator & Second Class Indicator \\
\cline { 2 - 3 } & Capital Factor Inputs & Fixed Asset Investment in Logistics \\
\cline { 2 - 3 } & Labour factor Inputs & Employment in Logistics \\
\cline { 2 - 3 } & Material factor Inputs & Freight Cars in Logistics \\
\cline { 2 - 3 } & Infrastructure Inputs & Road Miles \\
\hline Outputs & Economic Output in Logistics & Value Added in Logistics \\
\cline { 2 - 3 } & Scale of Output in Logistics & Cargo Turnover in Logistics \\
& & $\begin{array}{l}\text { Volume of Cargo Transported in } \\
\text { Logistics }\end{array}$ \\
\hline
\end{tabular}

\section{Static Analysis of Logistics Efficiency}

Table 2: Static analysis of supply efficiency in China's logistics industry: based on DEA model

\begin{tabular}{|c|c|c|c|c|c|c|}
\hline & \multicolumn{2}{|c|}{$\begin{array}{l}\text { Comprehensive } \\
\text { Efficiency }\end{array}$} & \multicolumn{2}{|c|}{$\begin{array}{ll}\text { Pure } & \text { Technical } \\
\text { Efficiency } & \\
\end{array}$} & \multicolumn{2}{|c|}{$\begin{array}{l}\text { Scale } \\
\text { Efficiency }\end{array}$} \\
\hline Regions & Averages & Ranking & Averages & Ranking & Averages & Ranking \\
\hline Beijing & 0.883 & 14 & 0.892 & 18 & 0.989 & 8 \\
\hline Tianjin & 1 & 1 & 1 & 1 & 1 & 1 \\
\hline Hebei & 1 & 1 & 1 & 1 & 1 & 1 \\
\hline Shanghai & 1 & 1 & 1 & 1 & 1 & 1 \\
\hline Jiangsu & 1 & 1 & 1 & 1 & 1 & 1 \\
\hline Zhejiang & 0.909 & 13 & 0.949 & 15 & 0.957 & 18 \\
\hline Fujian & 0.913 & 12 & 0.926 & 16 & 0.985 & 10 \\
\hline Shandong & 0.923 & 11 & 0.995 & 10 & 0.928 & 25 \\
\hline Guangdong & 0.813 & 18 & 0.968 & 12 & 0.840 & 28 \\
\hline Hainan & 0.671 & 23 & 1 & 1 & 0.671 & 29 \\
\hline Eastern & 0.911 & & 0.973 & & 0.937 & \\
\hline Shanxi & 0.820 & 17 & 0.836 & 21 & 0.980 & 13 \\
\hline Anhui & 1 & 1 & 1 & 1 & 1 & 1 \\
\hline
\end{tabular}




\begin{tabular}{l|l|l|l|l|l|l}
\hline Jiangxi & 0.846 & 15 & 0.871 & 19 & 0.972 & 14 \\
\hline Henan & 0.805 & 19 & 0.819 & 23 & 0.983 & 12 \\
\hline Hubei & 0.676 & 22 & 0.685 & 25 & 0.987 & 9 \\
\hline Hunan & 0.948 & 7 & 0.952 & 14 & 0.996 & 7 \\
\hline Central & 0.849 & & 0.860 & & 0.986 & \\
\hline Neimenggu & 1 & 1 & 1 & 1 & 1 & 1 \\
\hline Guangxi & 0.834 & 16 & 0.860 & 20 & 0.969 & 16 \\
\hline Chongqing & 0.778 & 20 & 0.831 & 22 & 0.934 & 23 \\
\hline Sichuan & 0.576 & 24 & 0.586 & 29 & 0.983 & 11 \\
\hline Guizhou & 0.931 & 10 & 0.964 & 13 & 0.965 & 17 \\
\hline Yunnan & 0.385 & 30 & 0.405 & 31 & 0.950 & 21 \\
\hline Tibet & 0.420 & 29 & 1 & 1 & 0.420 & 30 \\
\hline Shaanxi & 0.773 & 21 & 0.809 & 24 & 0.954 & 19 \\
\hline Gansu & 0.561 & 26 & 0.657 & 26 & 0.846 & 27 \\
\hline Qinghai & 0.368 & 31 & 0.914 & 17 & 0.403 & 31 \\
\hline Ningxia & 0.935 & 9 & 1 & 1 & 0.935 & 22 \\
\hline Xinjiang & 0.531 & 28 & 0.573 & 30 & 0.929 & 24 \\
\hline Western & 0.679 & & 0.800 & & 0.857 & \\
\hline Heilongjiang & 0.953 & 20 & 0.590 & 28 & 0.953 & 20 \\
\hline Jilin & 0.851 & 26 & 0.631 & 27 & 0.851 & 26 \\
\hline Liaoning & 0.970 & 15 & 0.971 & 11 & 0.970 & 15 \\
\hline Northeastern & 0.925 & & 0.731 & & 0.925 & \\
\hline Nationwide & 0.914 & & 0.861 & & 0.914 & \\
\hline & & & & & & \\
\hline
\end{tabular}

\section{Pure Technical Efficiency Analysis}

From Table 2, it can be seen that on a national scale, the pure technical efficiency shows a downward trend from 20102015, from 0.870 to 0.843 . And an upward trend from 2015-2019, from 0.843 to 0.893 . From a regional perspective, the average of pure technical efficiency in the eastern region was 0.973 , much higher than that other regions. The west and northeast were 0.8 and 0.731 , respectively, which were lower than the national average and less technically effective.

\section{Scale Efficiency Analysis}

From Table 2, it can be observed that the scale efficiency showed a declining trend from 0.930 to 0.901 during the period of 2010-2019. Six provinces, including Shanghai, Jiangsu, Anhui, and Inner Mongolia, have had scale efficiency values of 1 in the past 10 years, indicating that they have reached the optimal scale of production and that logistics resources have been effectively allocated and used.

\section{Comprehensive Efficiency Analysis}

From Table 2, it shows that the average of the comprehensive efficiency of logistics industry supply from the national level is from 0.808 in 2010 to 0.787 in 2019, showing a slight fluctuating downward trend in general. From the four regions, the eastern region has a comprehensive efficiency average of 0.911 , much higher than the other regions. The Central region has a mean comprehensive efficiency of 0.849 , slightly higher than the national average. The mean values of 0.679 and 0.680 in the west and northeast respectively are lower than the national average.

In summary, it can be seen that the comprehensive efficiency value of China's logistics industry has large differences between provinces and regions, and the imbalance of regional development is relatively serious, presenting the pattern of "East>Central>Northeast>West". 


\section{Dynamic Analysis of Logistics Efficiency}

By using DEAP 2.1 software, I conducted a dynamic analysis of supply efficiency in the logistics industry. Details are shown in Table 3.

Table 3 Malmquist Index Report for Logistics in 31 Provinces, 2010-2019

\begin{tabular}{llllllll}
\hline Regions & Effch & Techch & Tfpch & Regions & Effch & Techch & Tfpch \\
\hline Beijing & 0.979 & 1.043 & 1.021 & Neimenggu & 1 & 1.028 & 1.028 \\
Tianjin & 1 & 0.974 & 0.974 & Guangxi & 0.993 & 1.030 & 1.023 \\
Hebei & 1 & 1.046 & 1.046 & Chongqing & 1.022 & 1.018 & 1.041 \\
Shanghai & 1 & 1.025 & 1.025 & Sichuan & 1.016 & 1.023 & 1.039 \\
Jiangsu & 1 & 1.013 & 1.013 & Guizhou & 1.018 & 1.045 & 1.063 \\
Zhejiang & 1.014 & 1.025 & 1.039 & Yunnan & 1.064 & 1.023 & 1.089 \\
Fujian & 1.005 & 1.053 & 1.058 & Tibet & 0.947 & 1.078 & 1.021 \\
Shandong & 0.984 & 0.988 & 0.972 & Shaanxi & 0.974 & 1.016 & 0.990 \\
Guangdong & 1.015 & 1.027 & 1.042 & Gansu & 0.919 & 0.984 & 0.905 \\
Hainan & 0.978 & 1.013 & 0.991 & Qinghai & 0.982 & 1.008 & 0.989 \\
Eastern & 0.998 & 1.021 & 1.019 & Ningxia & 0.966 & 1.001 & 0.967 \\
Shanxi & 1.038 & 1.026 & 1.066 & Xinjiang & 1.043 & 0.993 & 1.036 \\
Anhui & 1 & 0.980 & 0.980 & Western & 0.995 & 1.021 & 1.016 \\
Jiangxi & 0.999 & 0.998 & 0.997 & Heilongjiang & 1.010 & 1.015 & 1.025 \\
Henan & 0.978 & 0.992 & 0.970 & Jilin & 0.997 & 1.011 & 1.008 \\
Hubei & 1.022 & 1.009 & 1.031 & Liaoning & 1.015 & 1.068 & 1.083 \\
Hunan & 1 & 1.022 & 1.022 & Northeastern & 1.007 & 1.031 & 1.038 \\
Central & 1.006 & 1.005 & 1.011 & Nationwide & 0.999 & 1.018 & 1.017 \\
\hline & & & & & & & \\
\end{tabular}

From Table 3, it can be seen that the national Malmquist Index increased by $1.7 \%$ to 1.017 during 2010-2019. The average value of technical efficiency and technical progress during the same period were 0.999 and 1.018 respectively, indicating that the growth in national TFP was mainly influenced by the increase in technical progress. From Table 4, it can be seen that the Malmquist index showed a decline in 2014-2016 and an increase in 2010-2014 and 2016-2019. Combined with Figure 1, the change of the Malmquist index basically maintains the same trend as the technological progress, which indicates that the Malmquist index is more obviously influenced by technological progress.

Table 4 Changes and Decomposition of the Malmquist Index in Logistics, 2010-2019

\begin{tabular}{llll}
\hline Years & Effch & Techch & Tfpch \\
\hline $2010-2011$ & 0.968 & 1.065 & 1.031 \\
$2011-2012$ & 0.989 & 1.108 & 1.097 \\
$2012-2013$ & 0.986 & 1.062 & 1.048 \\
$2013-2014$ & 1.001 & 0.892 & 0.893 \\
$2014-2015$ & 0.996 & 0.994 & 0.989 \\
$2015-2016$ & 1.038 & 0.927 & 0.963 \\
$2016-2017$ & 1.020 & 1.011 & 1.031 \\
$2017-2018$ & 0.984 & 1.078 & 1.061 \\
$2018-2019$ & 1.009 & 1.047 & 1.057 \\
Averages & 0.999 & 1.018 & 1.017 \\
\hline
\end{tabular}




\section{Conclusion}

The article conducts an empirical study of the inputs and outputs of China's logistics industry from both static and dynamic aspects and draws the following conclusions.

5.1 During 2010-2019, the development trend of China's logistics industry is positive, but the imbalance of regional development is more prominent, and the development level of the logistics industry presents the pattern of "East $>$ Central $>$ Northeast $>$ West".

5.2 The eastern logistics development is better but the growth rate slows down. The central and northeast followed by the east, logistics development efficiency is relatively lagging behind but the development prospects are broad, the investment needs to continue to increase. The western part of the logistics base is relatively backward, in the logistics scale and logistics technology has a lot of room for improvement.

5.3 The improvement of total factor productivity (TFP) of supply in China's logistics industry is greatly influenced by the advancement of logistics technology, and technological progress is the main source of TFP growth.

\section{Suggestion}

6.1 Strengthening regional coordination and integrating logistics resources by taking advantage of regional advantages. Strengthen cooperation between logistics enterprises in the eastern, central and western regions to complement each other's advantages.

6.2 Guided by the development concept of innovation, coordination, greentech, open-minded and mutural-share, to promote the high-quality development of the logistics industry.

6.3 Promote the development of high-quality logistics by improving total factor productivity. Improving the efficiency of resource utilization and optimizing resource allocation in the logistics industry.

\section{References}

XIAO Qian-wen,ZHANG Feng-rong,CHEN Ming. Decision-making and Judgment on the Reverse Logistics Enterprise -Based on Main Factor TOPSIS and Super-DEA Efficiency Analysis[J]Operations Research and Management Science,2017,26(09):193-199.

HAN Dong-ya, LIU Hong-wei. Study on Technology Efficiency of Logistics Industry in China and Influence Factors-An Empirical Study from Listed Companies[J]. China Business and Market,2019,33(11):17-26.

WANG Bo, ZHU Hong-hui, LIU Lin. Comprehensive Evaluation on Logistics Efficiency in the "The Belt and Road" in China_-Based on Three-stage DEA Model[J]. East China Economic Management,2019,33(05):76-82.

YU Jiali, QIAN Zhiwang. Logistics Industry Efficiency and Its Influencing Factors in Yangtze River Economic Belt[J]. Economic Geography,2018,38(08):108-115.

Cao Bingru, Kong Zeyun, Deng Lijuan. Evolution of Time and Space Efficiency of Provincial Logistics in the Yangtze River Economic Belt. Scientia Geographica Sinica,2019,39(12):1841-1848.

Mei Guoping, Gong Yaling, Wan Jianxiang, Ji Kaiwen. Study of the Efficiency Measurement of Logistics Industry in East China Based on Three-stage DEA Model[J]. Management Review,2019,31(10):234-241. 